\title{
Recent developments in loss of life and evacuation modelling for flood event management in the $\mathrm{UK}$
}

\author{
D. Lumbroso \& M. Di Mauro \\ HR Wallingford Ltd, Wallingford, Oxfordshire, UK
}

\begin{abstract}
To date the work done in the UK to assess the loss of life and evacuation times for flood risk areas has been limited. To provide the most accurate assessment of loss of life and evacuation times a complex model is required. This paper details the application of a prototype, agent-based Life Safety Model (LSM) to estimate the loss of life in two areas of the Thames Estuary. The LSM models individual receptors (e.g. people and cars) and their dynamic interaction with the floodwater. The LSM estimates deaths from: drowning; exhaustion; building collapse; and vehicles being swept away, as well as evacuation times.

The LSM offers a scientifically robust method of assessing residual risk behind flood defences and downstream of dams in terms of fatalities. Importantly, it allows the comparison of different emergency management strategies (e.g. the use of safe havens) that can assist in reducing the loss of life during future floods and dam breaks. The model was validated against historical data from the Canvey Island flood in 1953, during which 58 people lost their lives. The LSM was then applied to the Thamesmead embayment to assess the results for a range of scenarios.
\end{abstract}

Keywords: evacuation modelling, flood event management, loss of life.

\section{Introduction}

Despite the global impacts of floods there are a limited number of methods to estimate the loss of life and the evacuation times for flood events. Loss of life modelling can be performed at different levels of detail as follows:

- Macro or overall event level where one mortality rate is applied to the whole of the exposed population; 
- Meso or group/zone level where mortality rates are estimated for groups of people or specific zones;

- Micro or individual level where the circumstances and behaviour of each individual is modelled to estimate each person's probability of dying.

Until recently most of the loss of life models for floods were based on a statistical analysis of fatalities and injuries from historical events. Recent research has focused on the detailed simulation of individuals combined with a dynamic representation of the floodwater.

To date the work done in the UK to assess the loss of life and evacuation times for flood risk areas has been limited to macro or meso level estimates. The "Risk To People" model, developed as part of a Department for the Environment Food and Rural Affairs (Defra) research project, is the most commonly used tool in the UK to assess flood fatalities [1]. However, this meso-level method is based on an empirical, generalised model that does not use detailed information on each individual in its "broad scale" estimates of loss of life.

To provide the most accurate assessment of loss of life and evacuation times an agent based model is required. An agent-based model is a computational model that simulates the interactions of autonomous receptors with a view to assessing their effects on the system as a whole. It can model the simultaneous operations of multiple "agents" or receptors (in this case people and vehicles) with the floodwater, in an attempt to re-create and predict the actions of complex phenomena such as those that occur in flood emergency.

The modelling of the evacuation process generated by an approaching flood is important for those responsible for flood event management planning. It can identify "bottlenecks" in the escape network before they are experienced in an evacuation, it can also be used to determine the impact of road closures due to flooding, the impact of phased evacuation on traffic loading, and many other possible consequences of an evacuation event. In the UK there has been little work undertaken for evacuation modelling specifically for flood event management.

This paper describes the application of a recently developed, agent-based, micro-level Life Safety Model (LSM). This work was undertaken as part of Task 17 of the EC funded research project FLOODsite [2]. Rather than relying on very scarce and possibly unrepresentative observations on life loss caused by large floods, the LSM is designed to generate insightful information about this complex phenomenon by observing the simulated behaviour of a physicallybased virtual representation of the inundation area and its inhabitants as they mobilise to escape flooding. Details of the LSM are described below.

\section{The BC Hydro Life Safety Model (LSM)}

\subsection{Background}

The LSM is a piece of beta software developed by BC Hydro in Canada that previously had only been used to carry out dam break risk assessments for small communities (e.g. less than 3,000 people) in Canada. The LSM allows dynamic 
interaction between the receptors (e.g. people, vehicles and buildings) and the flood hazard. The LSM requires a significant amount of data including:

- The location of individual properties, vehicles and people;

- Flood depths and velocities from a two dimensional hydraulic model;

- Details of the road network and other pathways.

Figure 1 provides a conceptual view of the architecture of the LSM. The core of the system is the LSM Simulator that requires two inputs: an initial state of the world (which describes modelling receptors such as people, buildings, cars, roads) and the flood wave. The simulator output includes an estimated of loss of life and dynamic computer-graphics visualisations.

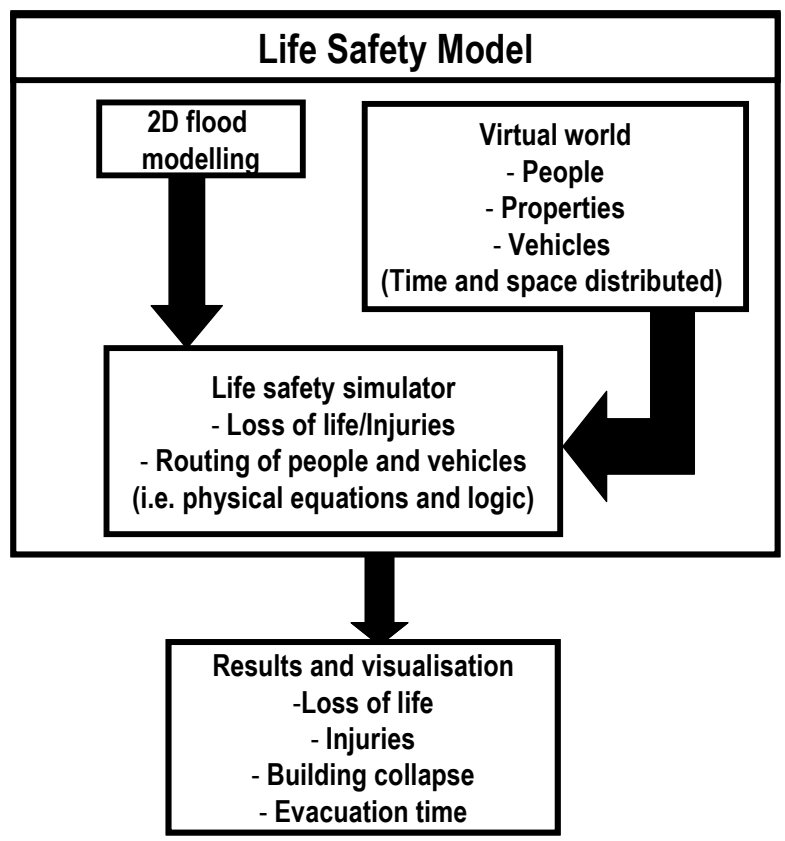

Figure 1: High-level architecture of the Life Safety Model [BC Hydro, 3, 4].

The system models the "fate" of a set of receptors, which are described by their position at each time step through the simulation. Each receptor can have a set of properties that describes its normal location/condition during a week, such as travel times, school/work hours, and weekend activities. Other time-varying properties include the ability of the receptor to withstand the effect of the flood wave, and how it would react to the approaching wave, with and without a formal evacuation warning.

The model uses a generalised event logic to determine the location of each object, whether it is aware of the flood wave, whether it is trying to find a safe haven, what happens if it encounters the flood, and whether the object survives 
or not. A loss function related to each receptor (e.g. people, buildings, vehicles) specifies the ability of an receptor to resist the impact from the flood wave, in terms of depth and velocity, and how these can change during an event. There can be instantaneous loss when an individual encounters fast-flowing water, or a group who have sought safety in a building can suffer cumulative loss if the building collapses or a slow deterioration in health if they are exposed to the flood water for a significant length of time, as a result of hunger or cold.

As a flood event evolves, the interaction of receptors with the flood wave will impact the ultimate loss of life. The timing of the event and the decisions made by individuals can determine whether or not they can escape the flood wave. As the flood progresses, escape routes can be eliminated by rising water, and with advancing time roads can become congested with evacuees.

The internal logic of the LSM can be explained by considering how an individual might experience a flood event. Figure 2 shows a person located in a building at the start of a flood event. Assuming that the area will be heavily inundated by floodwater, the person would be killed if caught in the building without warning in the location denoted by A in Figure 2. Three possible safe havens are shown to which the person can evacuate on foot or in a vehicle. Taking into account the "costs" to reach each haven, the south-west alternative is optimal for both foot and vehicle escape. However, if the person attempts escape

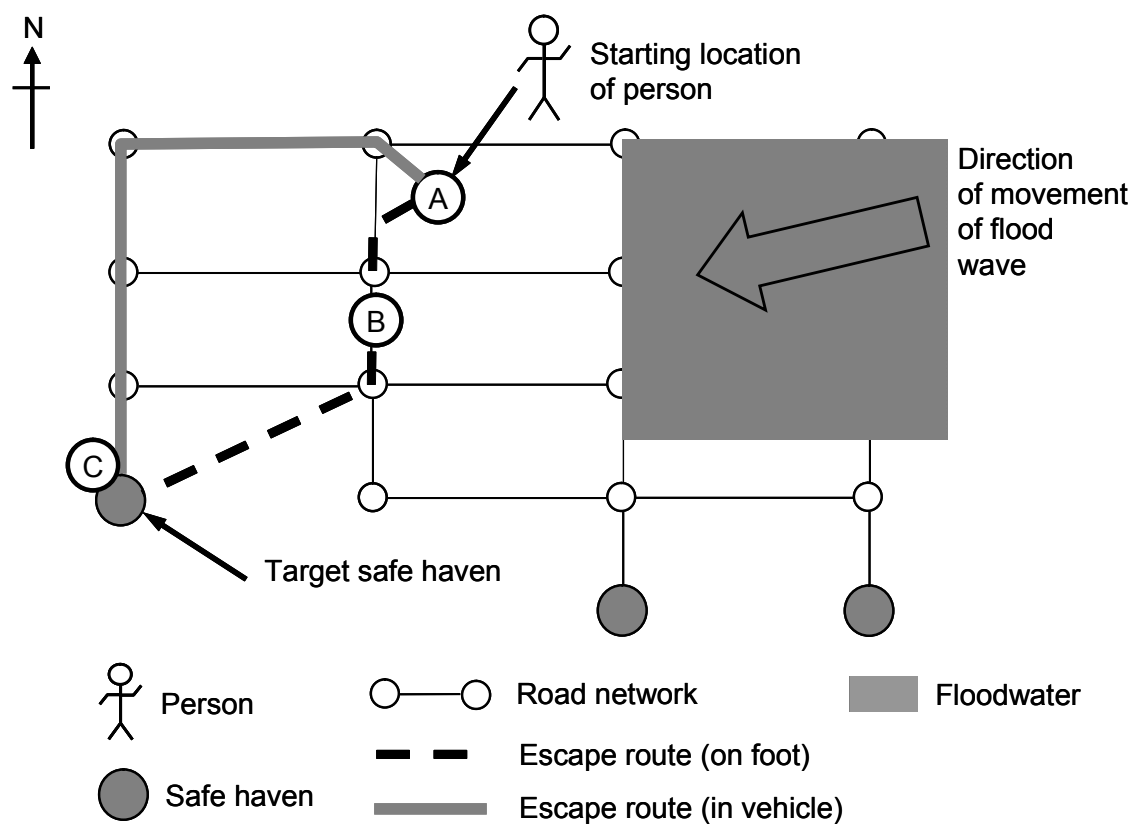

(Adapted from Johnstone et al. [5])

Figure 2: $\quad$ Fate diagram for a person in the LSM. 
on foot, they will be overwhelmed at point B. Under the third scenario, the person survives due to a combination of sufficient warning and the use of a vehicle to reach point $C$. The ability to generate and assess the outcomes of multiple scenarios is a key capability of the LSM [5].

\subsection{Application of the LSM in a UK environment}

As part of the research work was carried out to test the LSM in a UK environment. The aims of testing the LSM in the UK were as follows:

- To assess the possibility of employing the LSM for flood event management planning, rather than its original purpose of emergency planning for dam breaks;

- To assess whether it was possible to use the beta version of the LSM in the UK to estimate evacuation times for people using data readily available in the UK;

- To test if the LSM could be applied to 40,000 individual receptors in the UK. This number of receptors is an order of magnitude more than it had been applied in the past;

- To see whether it was possible to compare the results of the LSM in terms of evacuation times with other evacuation models developed for the project;

- To assess the accuracy of the estimates of loss of life and building collapse provided by the LSM.

\section{Application of the LSM to Canvey Island}

\subsection{Background}

Canvey Island, shown in Figure 3, is an island in the Thames Estuary, covering an area of $18.5 \mathrm{~km}^{2}$. The mean high water mark of the Thames Estuary at

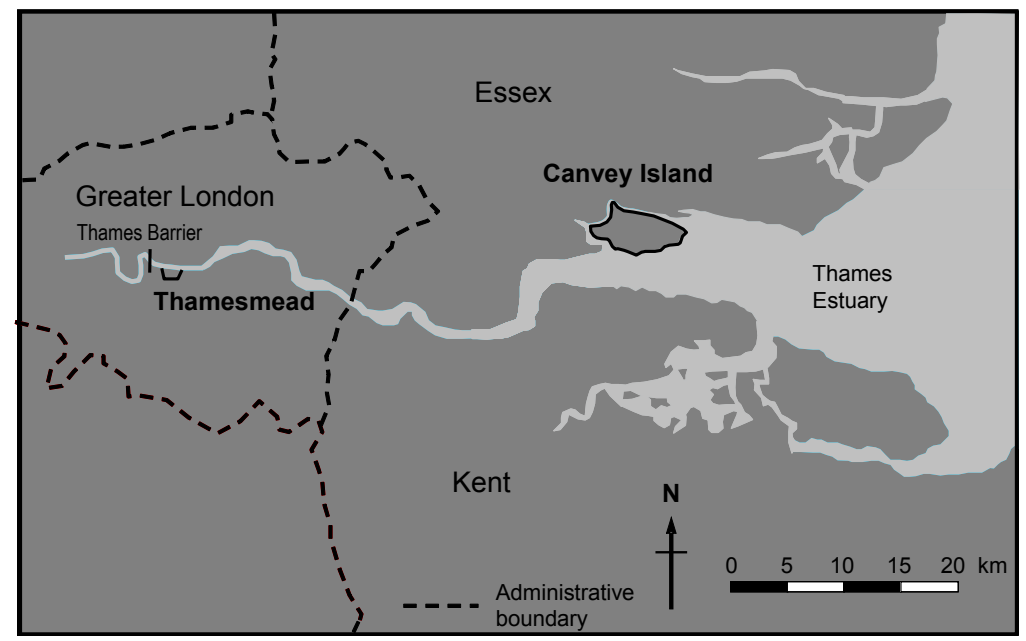

Figure 3: $\quad$ Location of Canvey Island and Thamesmead. 
Canvey Island is higher than most of Canvey Island's land. The first sea defences were constructed in 1623 and Dutch settlers formed the first Canvey Island communities of the modern era. The population did not expand rapidly until the 1920s, with 1,795 inhabitants in 1921 but over 6,000 in 1927 during which time the number of buildings rose from 300 to about 1,950 [6]. In 2001 its population was estimated to be approximately 37,000 [7].

In 1953 the island was inundated by the "Great North Sea Flood" that breached flood defences and resulted in the deaths of 58 people and the destruction of several thousand houses [8]. The likelihood of flooding of the access routes to and from Canvey Island will increase following sea level rise. Access to Canvey Island is currently only possible by two roads both of which are connected to the same roundabout. Any disruption to these routes would hamper evacuation and severely limit access.

At present, Canvey Island is protected by a concrete sea wall that rises approximately $3 \mathrm{~m}$ to $4 \mathrm{~m}$ above the high tide level. However, it has been found that whilst substantial, these defences show signs of deterioration such as cracks in the concrete, and the degradation of seals between slabs [6]. Although the current standard of protection at Canvey Island of $0.1 \%$ ( 1 in 1,000 years) will be reduced to $0.5 \%$ ( 1 in 200 years) by 2030 owing to sea level rise and the land in the south of the UK sinking.

On Canvey Island, it has been estimated that $30 \%$ of properties are bungalows and $45 \%$ of flats are situated at ground floor level, there is thus a large risk to life and property with limited opportunities to temporarily move to a higher level [6]. It is possible that a majority of the island would be inundated if a major storm surge occurred and led to major overtopping or breaching of defences.

\subsection{Available data}

One of the key tests of using the LSM in the UK was to assess whether there was sufficiently readily available data to utilise the model. The readily available data for Canvey Island comprised the following:

- Population data was available from the Office for National Statistics at an Output Area level. Output Areas contain an average of around 125 houses;

- Number of vehicles was available at an Output Area level is available from census data;

- Topographic data in the Thames Estuary LIDAR survey data was available with a vertical accuracy of approximately $\pm 25 \mathrm{~mm}$;

- The locations of properties were available in the form of a national property data set that provides geo-referenced details of each of the properties in England and Wales.

- The road network was digitised from street and Ordnance Survey maps;

These data were used to construct a "virtual" representation of the modelled areas that were used by the LSM. The majority of the effort expended in the work was related to setting up the virtual representation of the areas of interest. 


\subsection{Hydrodynamic modelling of the 1953 flood}

In order to model the 1953 Canvey Island flood a historical analysis was undertaken to reconstruct the situation that existed at that time. Important sources of information included: historical maps of the island; articles from 1953 newspapers; books (e.g. Barsby [8]); police reports; and the results of physical modelling carried out in 1954. This information was used to assist in assessing the height and location of the 1953 flood defences, to update the digital terrain model, to reconstruct the tidal shape and to assess the incoming flood volume associated with the breaches that occurred. The modelling of the 1953 inundation was carried out using the two dimensional software package TuFlow.

The results of the hydrodynamic model indicated that the 1953 flood covered most of Canvey Island. The model showed that the water depth was $3 \mathrm{~m}$ to $4 \mathrm{~m}$ at the point closest to the breach with a mean depth of between $0.8 \mathrm{~m}$ to $1.0 \mathrm{~m}$. The modelled volume of the 1953 flood was estimated to be 13.1 million $\mathrm{m}^{3}$. This compares well with a 1953 flood volume for Canvey Island of 11.7 million $\mathrm{m}^{3}$ that was estimated by the Kent and Essex River Board shortly after the event [9].

\subsection{Results for the 1953 flood}

The results of the reconstruction of the 1953 flood event agreed well with the available historical data. The BC Hydro LSM model indicated that approximately 100 to 120 fatalities had occurred during the 1953 event. This number is dependent on the "resilience factors" applied to both people and buildings. The actual number of people that died in 1953 was 58 . The number of buildings destroyed during event is unclear. However, the anecdotal evidence available seems to be similar to the LSM model results. Figure 4 shows the

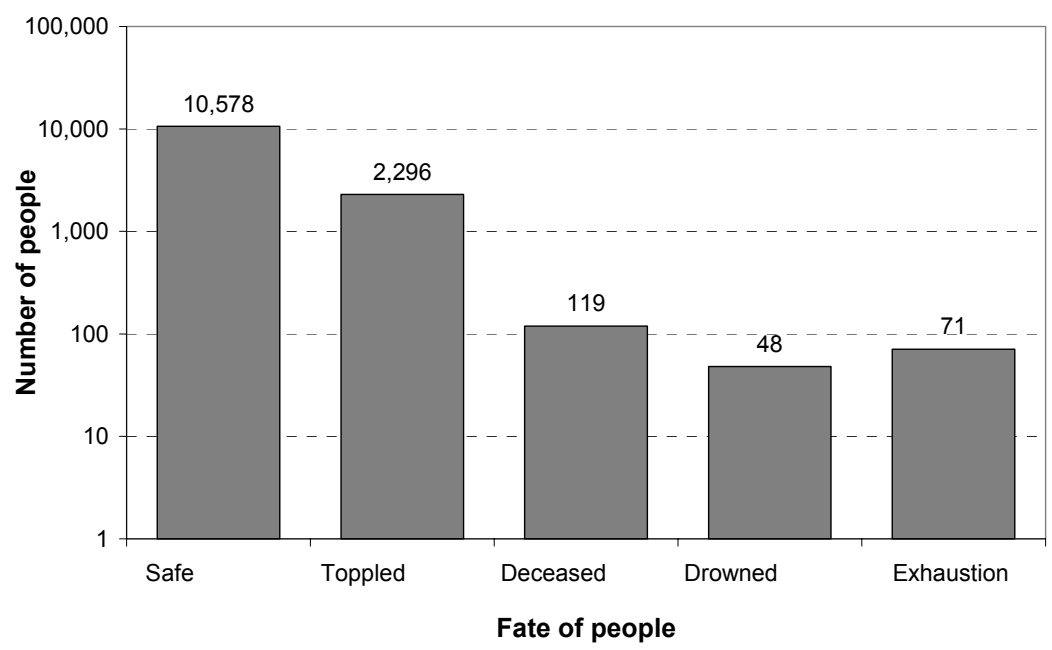

Figure 4: Typical results of modelling the fate of people for the 1953 Canvey Island flood. 
results of the loss of life modelling using the LSM for the 1953 flood. Of the 13,000 people living on the island in 1953 the model indicated that there would be 119 fatalities, 48 the result of drowning and 71 as a result of exhaustion. The LSM also indicated that some 2,300 would be "toppled" (i.e. knocked over) by the floodwater. This figure can be used as a proxy for the number of injuries that are likely to occur.

\section{Application of the LSM to Thamesmead}

Having validated the LSM on Canvey Island it was also applied to the Thamesmead embayment located downstream of the Thames Barrier (Figure 1), which has a population of 43,000 . Sixty different scenarios were modelled for the Thamesmead embayment. These included different rates of warning; numbers of road closures and safe havens. For the 60 different scenarios modelled the number of fatalities varied from a minimum of 406 to a maximum of 2,378 people. The average number of fatalities was found to be 1,296 . There are approximately 43,000 people that are exposed to the flooding in the Thamesmead embayment, so the LSM model indicates that on average about 3\% of the exposed population will suffer fatalities. Research by Jonkman [10] indicates that the expected number of fatalities is usually between $0.7 \%$ and $1.3 \%$ of the exposed population. This is shown in Figure 5. However, in these cases many of the population have evacuated before the hazard occurred. For Thamesmead the "worst case" of everybody being at home was assumed. In the historical data collected by Jonkman [10] many of the people had already been evacuated from the exposed area so it is expected that in the case of Thamesmead where it was assumed that no evacuation would occur prior to the flood event that the percentage of fatalities would be much higher.

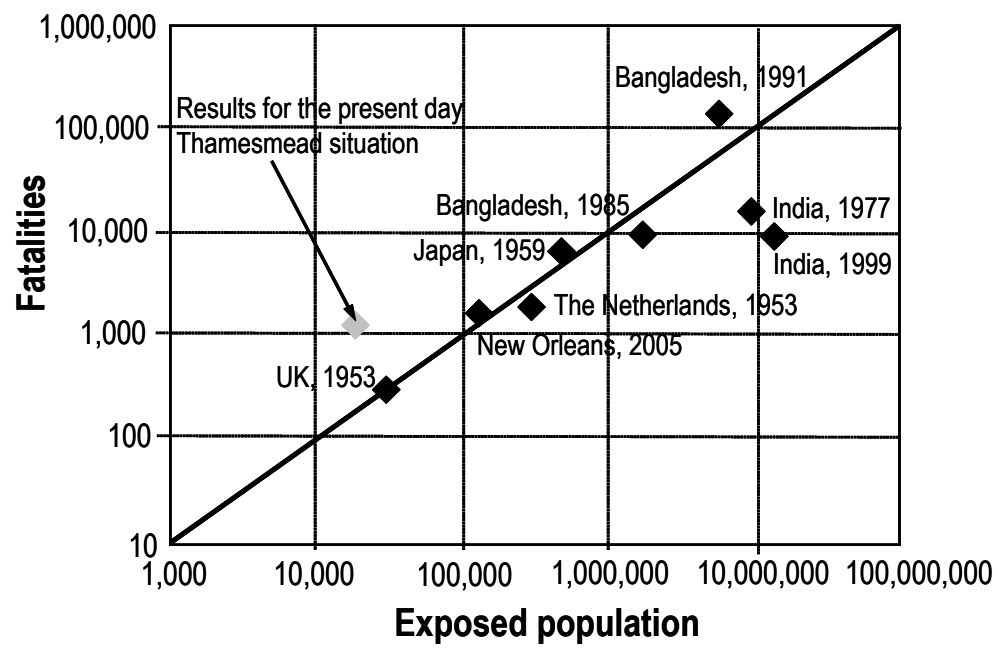

(Source: Adapted from Jonkman [10])

Figure 5: Results of Thamesmead modelling compared with historical data. 
The LSM indicated that the time required for 43,000 people to evacuate the Thamesmead embayment varied between approximately 5 and 8 hours, depending on the number of safe havens assumed and the capacity of the road network. These evacuation times were compared against evacuation times estimated using other methods and found to be realistic.

\section{Conclusions}

The LSM offers a scientifically robust method of assessing residual risk behind flood defences and downstream of dams in terms fatalities. Although time consuming to set up the LSM provides not only can evacuation but also models also computes the injuries and loss of life for each method. The LSM model is the only model that has a dynamic interaction between the receptors (e.g. people, vehicles) at risk and the flood hazard. Other loss of life and evacuation models only generally provided first order of magnitude in terms of the evacuation times and fatalities. These could be useful at high level planning stage but are unlikely to be useful for detailed emergency planning

Importantly, the LSM allows the comparison of different emergency management strategies (e.g. the use of safe havens) that can assist in reducing the loss of life during future floods and dam breaks. The model was validated against historical data from the Canvey Island flood in 1953, during which 58 people lost their lives. The LSM was then applied to Thamesmead to estimate loss of life and evacuation times for a range of scenarios.

\section{References}

[1] Defra, R\&D outputs: Flood Risks to People Phase 2 FD2321/TR1 The Flood Risks to People Methodology, March 2005

[2] Lumbroso, D, Gaume, E, Logtmeijer, C, Mens, M \& van der Vat, M Evacuation and traffic management, FLOODsite Task 17 report number T17-07-02, March 2008

[3] BC Hydro, Life Safety Model (LSM) formal description engineering report E299, October 2004

[4] BC Hydro, Life safety modelling environment V2.0 beta User manual, August 2006

[5] Johnstone, W.M., Sakamoto, D., Assaf, H. \& Bourban, S. Architecture, modelling framework and validation of BC Hydro's virtual reality life safety model International Symposium on Stochastic Hydraulics 2005, 23 \& 24 May 2005, Nijmegen, The Netherlands

[6] Kelman, I Physical flood vulnerability of residential properties in coastal, eastern England, Dissertation submitted for the degree of Doctor of Philosophy, September 2002, University of Cambridge, UK

[7] Office For National Statistics, The 2001 census in England and Wales [WWW] http://www.statistics.gov.uk/census/

[8] Barsby, G Canvey Island, Tempus Publishing Limited, Gloucestershire, UK, 1997 
272 Flood Recovery, Innovation and Response I

[9] Allen, F. H., Price, W.A. \& Inglis, C.C. Model experiments on the storm surge of 1953 in the Thames Estuary and the reduction of future surges Proceedings of the Institution of Civil Engineers 1954 Vol 4 Pt III pp 48-83

[10] Jonkman, B Loss of life estimation in flood risk assessment - Theory and applications Dissertation submitted for the degree of Doctor of Philosophy, June 2007, Technical University of Delft, The Netherlands 